\title{
Saudi dental students' opinions on the qualities and attributes of an effective dental teacher
}

This article was published in the following Dove Press journal:

Advances in Medical Education and Practice

23 September 2016

Number of times this article has been viewed

\author{
Asma M Al-Jobair \\ Maha A AISarheed \\ Department of Pediatric Dentistry \\ and Orthodontics, College of \\ Dentistry, King Saud University, \\ Riyadh, Saudi Arabia
}

Objective: To evaluate Saudi dental students' opinions on the qualities and attributes of an effective dental teacher.

Methods: This cross-sectional study was conducted between March and May 2014 at the College of Dentistry, King Saud University. Self-administered questionnaires were distributed to all students enrolled in the 2013/2014 academic year. The questionnaire contained 43 items regarding students' opinions on the qualities and attributes of a good dental teacher. The attributes were grouped into two main categories: performance and personality. Mean and standard deviations were calculated for each item and then for the whole category. Performance and personality were compared between male and female students and between junior and senior students using Mann-Whitney $U$ test.

Results: Four hundred and seventy-seven questionnaires were completed, representing a response rate of $79 \%$. Performance attributes were significantly more important than personality attributes to Saudi dental students $(P<0.001)$. Perceptions of performance and personality attributes did not differ between male and female students; however, junior students put more emphasis on personality attributes than senior students.

Conclusion: Saudi dental students consider performance attributes more important than personality attributes for their successful learning. Teachers' educational skills are valued more than the attributes, which do not connect directly to students' learning process.

Keywords: perceptions, dental students, characteristics, dental teacher

\section{Introduction}

The quality of students' educational experience is strongly linked to the motivation and skills of their instructors. It is suggested that without good teachers, there will be no good education. ${ }^{1}$ Medical education has undergone large changes in the recent times as the focus has shifted from a teacher-centric to a student-centric approach. However, the importance of teacher in education process still persists. ${ }^{2}$ This is because besides being the information provider, the teacher is expected to be facilitator, role model, assessor, planner, and resource developer. ${ }^{3}$ A good teacher is one who focuses on the students' learning, responds to students' content requests, and conveys knowledge: which means that a teacher is more than simply an information provider. ${ }^{4}$

Many studies have been conducted to identify the attributes and qualities of a good undergraduate teacher. Qualities of effective teachers compiled from these studies are generally categorized into professional and personal qualities. A good teacher is a good
Correspondence: Asma M Al-Jobair Department of Pediatric Dentistry and Orthodontics, College of Dentistry, King Saud University, PO Box 60169, Riyadh I I545, Saudi Arabia Email aaljobair@ksu.edu.sa 
communicator; is knowledgeable, respectful, supportive; is someone who explains well, uses different modalities, builds relationships; is organized and motivating; makes learning interesting; teaches for understanding; is involving and caring. .,4-7 $^{1,7}$

However, differences in the structure and content of different disciplines suggest that some qualities of effectiveness may be discipline-specific; the learning process may be unique to the discipline and requires unique instructional methods. ${ }^{8}$ This is likely true of dentistry. Teaching in the dental environment is a challenging task, and many dental teachers engage in teaching without sufficient orientation or training. ${ }^{9}$ Consequently, effective dental teachers may have different characteristics to teachers in other disciplines. Several roles have previously been described for teachers who teach in clinical environment. ${ }^{3}$ These roles require the teacher to be more than a dental expert - a teacher who plays many roles concurrently, moving from one role to another during the same session.

Generally, the dental curriculum at the College of Dentistry, King Saud University consists of multiple phases that expose students to different teachers. The curriculum begins with basic science courses that are taught by science teachers. After that, medical courses are introduced, such as physiology and anatomy, which are delivered to the dental students by medical teachers. Then, basic dental courses are given to the students theoretically by dental teachers. This is followed by practical dental courses, and finally by clinical courses (patient-centered) under the supervision of dental faculty members. Therefore, clinical teaching in dentistry is a three-way dynamic between teacher, patient, and student. As a result, the dental curriculum is exceptional, and requires dental students to attain diverse proficiencies, including theoretical knowledge, clinical competencies, and interpersonal skills. ${ }^{9}$ Above all, a good dental teacher is required to maximize the fulfillment of these outcomes through different approaches. The performance by teachers and learning outcomes by the students can be improved greatly if the attributes and qualities of teacher are understood in light of their impact on the earlier mentioned variables.

In order to determine the role of the teacher in promoting interest and achievement in dentistry, as well as the teacher's influence on students' education and interest in the subject, it is important to investigate how dental students perceive their teachers on the dimensions of personality and performance. It is imperative to assess the perspectives of the dental students themselves, as they are the individuals who are most specifically affected by dental teachers. Students must be included in determining what efforts will improve their learning. Although several studies have recognized, from the students' and teachers' perspectives, the qualities of an effective dental teacher in different universities and countries such as USA, Canada, Australia, and Malaysia, ${ }^{10-13}$ no previous study in Saudi Arabia had investigated the Saudi dental students' perception toward their teachers. Cultural and educational factors play a large role in the difference in perception. ${ }^{14}$ Understanding these factors should be borne in mind when interpreting students' thinking and behavior. ${ }^{14}$

Therefore, the aim of this study was to evaluate the Saudi dental students' opinions on the qualities and attributes of an effective dental teacher. Evaluating the students' perceptions toward their teachers and determination of the central characteristics of a viable dental teacher are important to advance successful dental education. The significance of counting student feedback in the process of education is considered the key element used to observe the quality and distinction of academic programs.

\section{Materials and methods}

The study proposal was approved by the Ethical Committee of the College of Dentistry Research Center at King Saud University (FR0146). This cross-sectional study was conducted between March and May 2014 at the College of Dentistry, King Saud University in Riyadh, Saudi Arabia. An English questionnaire previously developed and used by Al-Mohaimeed and Khan was used in the current study with their permission. ${ }^{15}$ The questionnaire was evaluated and subjected to content validation by three experts in medical education. In addition, the questionnaire was pretested on a small number of medical students and was then modified accordingly. ${ }^{15}$

Although all items in the questionnaire were validated in terms of content in the previous study, ${ }^{15}$ the questionnaire was further evaluated by two dental faculty members to ensure appropriateness for dental students and dental teachers. Also, the questionnaire was pilot tested on 20 dental students, after which slight modifications were made.

Self-administered English questionnaires with a covering letter explaining the purpose of the study were distributed to all students enrolled in the 2013/2014 academic year. Permission to distribute the questionnaires was obtained from a course director in each class (from year 1 to year 5). The questionnaires were handled by the first investigator to the course directors to be distributed in the classroom 10 minutes before the end of the lecture. The questionnaires were recollected by the same investigator in the same lecture room. 
Contribution was voluntary and students' responses were kept anonymous. Completing and returning the questionnaire constitutes a consent to participate.

The questionnaire contained 43 items regarding the students' opinions on the qualities and attributes of good dental teachers. A statement was a typical questionnaire item. Each item was measured on a five-point Likert scale with the following response options: $5=$ strongly agree, $4=$ agree, $3=$ not sure, 2 = disagree, and $1=$ strongly disagree. The items were grouped into two main categories: performance and personality. Twenty-five attributes pertained to performance and the remaining 18 attributes pertained to personality.

Mean and standard deviations were calculated for each item, and then the mean and standard deviations were calculated for all items in each category. Performance and personality were compared between male and female students and between junior (years 1-3) and senior students (years 4-5). Data were not normally distributed and Mann-Whitney $U$ test was used for statistical comparison. The alpha level for statistical significance was set at $<0.05$. Analyses were performed using Statistical Package for Social Sciences software, version 20 (IBM Corporation, Armonk, NY, USA).

\section{Results}

In total, 604 questionnaires were distributed, and 477 questionnaires were completed and returned by the students, representing a response rate of $79 \%$. Out of 477 participants, there were 260 male (54.5\%) and 217 female (45.5\%) students. The highest number of participants was 123 from the first year $(25.8 \%)$, while the smallest number was 80 from the fifth year $(16.8 \%)$.

Table 1 shows the itemized list of performance and personality attributes along with the mean score of each item. Among the performance attributes, the top items were expertise, good command on clinical skill, being able to understand/relate to students, making the students feel comfortable, and understanding the role of the teacher. The attributes that were the least endorsed were sharing personal experiences and telling jokes. Among the personality attributes, the top items were being respectful to students, having good communication skills, being helpful, honest, and emotionally controlled, whereas the least endorsed were having a good sense of humor, being self-sacrificing, and giving good marks to all students.

The reliability of performance and personality categories was calculated using Cronbach's alpha coefficient and was found to be 0.95 . Generally, as shown in Table 2, performance attributes were more important than personality attributes for the dental students, with this difference being statistically significant $(P<0.001)$. Both male and female students rated performance and personality attributes as equally important, and there was no significant difference between sexes in terms of performance or personality. However, personality attributes were statistically significant class-wise. Junior dental students recognized the importance of personality attributes more the than seniors $(P=0.01)$, whereas performance attributes were rated equally among them.

\section{Discussion}

Our current study assembled dental students' perceptions about the importance of certain qualities of dental teachers. Their perceptions were used to assimilate a list of teachers' core qualities in two domains: performance and personality, with the assumption that good teaching helps all dental students to improve their interest in studies. The assumption was also made that effective learning is dependent upon the efficacy of the teacher. The respondents believe that quality education begins with quality teachers; most of the students rated teaching quality as improving if the teacher had a friendly attitude, was punctual, enthusiastic, and tolerant.

Several studies have investigated the qualities and attributes of an excellent dental teacher, both as a classroom teacher and a clinical supervisor. There were some differences in the qualities and attributes between classroom teachers and clinical supervisors caused by the differences in teaching environment. Schönwetter et al identified seven categories of effective teacher which were as follows: individual rapport, organization, enthusiasm, learning, group interaction, exams, and assignments. ${ }^{11}$ Effective teaching in the classroom was best defined by organization and rapport, whereas in the clinic, rapport was the most frequently described behavior. ${ }^{11}$ Murphy et al showed that students prefer teachers who use strong visual presentations and facilitate note-taking during lectures. ${ }^{16}$ However, Jahangiri et al reported that students mostly valued the clinical teachers who were caring, motivating, and empathetic. ${ }^{17}$ In the present study, however, no attempt was made to differentiate between the teachers as lecturers or clinical supervisors, as all dental teachers at King Saud University are involved in lecturing, laboratory training, and clinical supervision, with no specific teacher for any individual teaching category. Nevertheless, learning preferences of some dental students may be altered as the learning environment changes from classroom to preclinical laboratory, and then to clinical hall. Dental educators should 
Table I List of attributes on performance and personality and mean score of each item in descending order

\begin{tabular}{|c|c|c|}
\hline Categories & Attributes & Mean score \pm SD \\
\hline \multirow[t]{25}{*}{ Performance } & Expert on the subject /knowledgeable & $4.72 \pm 0.501$ \\
\hline & Good command on clinical skills/teaches the practical useful points & $4.64 \pm 0.618$ \\
\hline & Understands/relates to students & $4.64 \pm 0.655$ \\
\hline & Makes students feel comfortable & $4.63 \pm 0.688$ \\
\hline & Understands the role of teacher & $4.63 \pm 0.636$ \\
\hline & Teaching at the student level & $4.62 \pm 0.643$ \\
\hline & Motivates students & $4.62 \pm 0.602$ \\
\hline & Available for consultation/advice & $4.61 \pm 0.586$ \\
\hline & Good planner and organizer of the course/curriculum & $4.59 \pm 0.624$ \\
\hline & Good guidance provider & $4.57 \pm 0.630$ \\
\hline & Desires to promote student's learning & $4.57 \pm 0.653$ \\
\hline & Organizes good lectures/use of audiovisual aids, for example, power point & $4.57 \pm 0.629$ \\
\hline & Good examiner/makes/asks good questions relevant to the students' learning needs in exam & $4.57 \pm 0.663$ \\
\hline & Helps in facilitation of students' learning & $4.57 \pm 0.585$ \\
\hline & Develops good learning resource materials for students, including study guides (Internet based or printed) & $4.55 \pm 0.710$ \\
\hline & Monitors students' progress/is interested & $4.50 \pm 0.694$ \\
\hline & Interacts with students & $4.50 \pm 0.692$ \\
\hline & Sensitive to students' problems/needs & $4.49 \pm 0.706$ \\
\hline & Good role model & $4.48 \pm 0.723$ \\
\hline & Asks for feedback from students/tries to improve according to their needs & $4.47 \pm 0.726$ \\
\hline & Offers good mentoring & $4.46 \pm 0.690$ \\
\hline & Good skills as problem-based learning facilitator & $4.44 \pm 0.727$ \\
\hline & Maintains his/her decorum as a teacher & $4.29 \pm 0.803$ \\
\hline & Explains and shares personal experiences & $4.22 \pm 0.956$ \\
\hline & Tells jokes/funny stories during lectures/session to amuse students to maintain their interest & $4.01 \pm 0.963$ \\
\hline \multirow[t]{18}{*}{ Personality } & Respectful to students & $4.75 \pm 0.519$ \\
\hline & Good communication skills & $4.72 \pm 0.575$ \\
\hline & Helpful & $4.69 \pm 0.544$ \\
\hline & Honest & $4.64 \pm 0.566$ \\
\hline & Emotionally controlled/does not get angry easily & $4.60 \pm 0.751$ \\
\hline & Friendly & $4.55 \pm 0.770$ \\
\hline & Accessible & $4.54 \pm 0.770$ \\
\hline & Tolerant/patient & $4.54 \pm 0.646$ \\
\hline & Good listener & $4.53 \pm 0.737$ \\
\hline & Open minded & $4.44 \pm 0.712$ \\
\hline & Nonjudgmental & $4.43 \pm 0.868$ \\
\hline & Punctual & $4.38 \pm 0.751$ \\
\hline & Enthusiastic & $4.35 \pm 0.799$ \\
\hline & Dresses appropriately & $4.24 \pm 0.823$ \\
\hline & Not strict/shows leniency & $4.04 \pm 1.042$ \\
\hline & Good sense of humor & $4.03 \pm 0.937$ \\
\hline & Self-sacrificing & $3.95 \pm 0.969$ \\
\hline & Gives good marks to all students & $3.71 \pm 1.283$ \\
\hline
\end{tabular}

Abbreviation: SD, standard deviation.

be aware of these differences in order to investigate how to improve teaching for dental students.

Generally, the results of the present study are in agreement with previous studies that recognized enviable attributes and qualities of a good dental teacher from the students' perspectives. ${ }^{11,12,17}$ In the performance category, dental students rated being "expert in the subject" and being "good in clinical and practical commands" as the highest attributes of a good teacher. This seems logical, as the major component of dentistry involves clinical and practical courses which require the teacher to be knowledgeable and highly skilled. The combination between knowledge and clinical training is considered to be integral to dental education.

Several studies have reported increased stress among Saudi dental students. ${ }^{18,19}$ This may account for the propensity to consider a good dental teacher as someone who "understands/relates to students" and "makes students feel comfortable". Working in stressful situations, such as dentistry, necessitates teachers to be understandable and empathic. However, some attributes were not well regarded, 
Table 2 Relationship between performance and personality attributes and general characteristics of the respondents

\begin{tabular}{|c|c|c|c|c|c|c|c|}
\hline \multirow[t]{2}{*}{ Variables } & \multirow[t]{2}{*}{ No. } & \multicolumn{3}{|c|}{ Performance } & \multicolumn{3}{|l|}{ Personality } \\
\hline & & Mean \pm SD & Sum of rank & $P$-value* & Mean \pm SD & Sum of rank & $P$-value \\
\hline \multicolumn{8}{|l|}{ Sex } \\
\hline Male & 260 & $4.52 \pm 0.459$ & 63,937 & 0.230 & $4.40 \pm 0.47 \mid$ & 63,074 & 0.533 \\
\hline Female & 217 & $4.50 \pm 0.415$ & 50,065 & & $4.39 \pm 0.439$ & 50,929 & \\
\hline \multicolumn{8}{|l|}{ Class } \\
\hline Junior & 300 & $4.52 \pm 0.462$ & 73,635 & 0.183 & $4.43 \pm 0.467$ & 76,427 & 0.01 \\
\hline Senior & 177 & $4.50 \pm 0.400$ & 40,367 & & $4.32 \pm 0.430$ & 37,576 & \\
\hline \multicolumn{8}{|l|}{ Categories } \\
\hline Performance & & $4.52 \pm 0.439$ & & & & & \\
\hline Personality & 477 & $4.39 \pm 0.457$ & & & 0.001 & & \\
\hline
\end{tabular}

Note: *Mann-Whitney $U$ test.

Abbreviation: SD, standard deviation.

such as "explains/shares personal experiences", "tells jokes/ funny stories during lectures", and having a "good sense of humor". This result is quite surprising, as the students prefer the teacher who understands/relates to students and makes them feel comfortable, but, at the same time, prefer the teacher without a sense of humor/tell jokes. This may be attributed to the nature of dental practicality. Dental students are known to be practical students. Being in stressful situations is not militated against by telling jokes or by having a sense of humor, but rather by being respected and effectively communicated. This is reflected by students' selection of being "respectful to students" and having "good communication skills" as the highest chosen personal attributes. Dental students in this study and in other studies were looking for a teacher who is "respectful to students". Al-Kabbaa et al assessed the perceptions of medical students toward the learning environment in a new medical school in Saudi Arabia. ${ }^{20}$ One of the evaluated scales was students' perceptions of teachers, where the students gave poor ratings and were the lowest across all investigated areas. The students felt that the teachers were strict and, at times, sarcastic about the students' shortcomings. Similarly, Ciraj et al found that motivation, defining objectives, communication, and showing respect to students were the major factors that students want to see in their teachers. ${ }^{21}$

In this study, students believed that teachers should use a variety of teaching methods and instructional strategies that address the learning abilities and styles of all students without sacrificing high expectations. Although most of the students in any discipline are motivated by good marks, dental students did not have a positive perception of a teacher who gives good marks to all students. Dental college is highly competitive, and dental students realize the value of competition. Therefore, giving good marks to all students was perceived as unfair.
Performance attributes were more important than personality attributes to the Saudi dental students. This is in disagreement with Jahangiri and Mucciolo who found that students put greater weight on teachers' personality than performance. ${ }^{10}$ However, Slate et al found that most of the shared characteristics of effective teachers were cognitive aspects of instruction rather than personal traits of the teacher. ${ }^{6}$ Also, this result was similar to the perception of Saudi medical students, as reported by Al-Mohaimeed and Khan. ${ }^{15}$ Such a result might be related to the surrounding environment which required knowledge and practice to a great extent, or might be related to the sociocultural background.

Both male and female students rated performance and personality attributes equally important for their successful learning. However, personality was viewed as more important by junior students compared to senior students, perhaps because they are not yet engaged in clinical courses which require optimal performance. Nevertheless, when looking at the overall results, it seems that performance and personality attributes are both imperative and cannot be separated from each other.

From the students' viewpoint, it is obvious that teachers' role is still valid through the demanding qualities and attributes needed to be well regarded. Teachers impact upon students' learning and achievement more than any other factor and impactful teaching practices are the most effective strategy for improving student learning. ${ }^{1}$ Many influences, such as educational history, personality, intelligence, culture, clinical skills, behavior, body language, attitude, and open-mindedness, can affect how a student perceives a particular teacher at any given time, and the students surveyed in this study were asked to look backward in time. In our study, the perception of Saudi dental students at the College of Dentistry, King Saud University was relatively 
homogenous in terms of thoughts on the educational process. It is, however, a snapshot of one group of student opinions at one point in time.

Although the study assessed teacher performance and personality effectiveness on a range of items, some limitations remain due to the nature of questions. Responses were open to demand characteristics, as the students may have responded in the way that they thought they were expected to. Moreover, there were no items other than the performance and personality characteristics. Introduction of such items in the survey would have allowed crosschecking the responses of students to assess whether they responded according to the ascribed value or just randomly. Additional limitation is that the demographics of those students who did not participate were not collected. However, it is unlikely that the responses were biased in this way; the no-responses rate of $21 \%$ is in the acceptable range for a survey. Furthermore, data were collected from one dental college in Saudi Arabia, and the results cannot be generalized to all Saudi dental students.

The results of this study are useful and the areas of research can be expanded with respect to this topic. More research subjects could be included to get better, more detailed, and accurate results. For this purpose, teachers could be included in the survey to find out reasons behind certain behaviors. This will allow for better understanding of the relationship between the teaching efficacy and quality. Another area where research can be expanded is in terms of methodology. The current study used only quantitative methods but could have included in-depth interviews and field observations to get diversified data. In addition, the research area could be extended to include students from different dental colleges in Saudi Arabia.

It was deduced in the study that the perceptions of Saudi dental students at the College of Dentistry, King Saud University relate to share voice with those who impact the educational process. The findings of the current study can be used to employ, recruit, and develop better faculty members; to enhance faculty members' teaching skills; and to arrange for continuing educational programs. Accordingly, the authorities can prioritize their educational needs and improve the quality of dental education programs.

\section{Conclusion}

Saudi dental students consider teachers' performance attributes more important than personality attributes for their successful learning. Teachers' educational skills are valued more than the attributes, which do not directly impact upon students' learning. Although the current system of education promotes student-centered education, certain qualities and attributes of teachers are still important.

\section{Acknowledgments}

The authors would like to acknowledge Dr Al-Mohaimeed and Dr Khan for giving permission to use the questionnaire. The authors would also like to acknowledge the contribution of the dental students from King Saud University. This study was registered at the College of Dentistry Research Center, King Saud University (FR0146).

\section{Disclosure}

The authors report no conflicts of interest in this work.

\section{References}

1. Stronge JH, Ward TJ, Grant LW. What makes good teachers good? A cross-case analysis of the connection between teacher effectiveness and student achievement. J Teach Educ. 2011;62(4):339-355.

2. Dath D, Iobst W. The importance of faculty development in the transition to competency-based medical education. Med Teach. 2010;32(8): 683-686.

3. Harden RM, Crosby JR. AMEE Guide No 20: The good teacher is more than a lecturer: the twelve roles of the teacher. Med Teach. 2000; 22(4):334-347.

4. Stenfors-Hayes T, Hult H, Dahlgren LO. What does it mean to be a good teacher and clinical supervisor in medical education?. Adv Health Sci Educ Theory Pract. 2011;16(2):197-210.

5. Wang J, Gibson AM, Slate JR. Effective teachers as viewed by students at a 2 year college: a multistage mixed analysis. Issues Educ Res. 2007;17(2):1-24.

6. Slate JS, LaPrairie K, Schulte DP, Onwuegbuzie AJ. A mixed analysis of college students' best and poorest college professors. Issues Educ Res. 2009;19(1):61-78.

7. Aulls MW. Students' experiences with good and poor university courses. Educ Res Eval. 2004;10(4-6):303-335.

8. Muijs D, Campbell J, Kyriakides L, Robinson W. Making the case for differentiated teacher effectiveness: an overview of research in four key areas. Sch Eff Sch Improv. 2005;16(1):51-70.

9. Kumar S, Dagli RJ, Mathur A, Jain M, Prabu D, Kulkarni S. Perceived sources of stress amongst Indian dental students. Eur J Dent Educ. 2009;13(1):39-45.

10. Jahangiri L, Mucciolo TW. Characteristics of effective classroom teachers as identified by students and professionals: a qualitative study. J Dent Educ. 2008;72(4):484-493.

11. Schönwetter DJ, Lavigne S, Mazurat R, Nazarko O. Students' perceptions of effective classroom and clinical teaching in dental and dental hygiene education. J Dent Educ. 2006,70(6):624-635.

12. GerzinaTM, McLeanT, FairleyJ. Dental clinical teaching: perceptions of students and teachers. J Dent Educ. 2005;69(12):1377-1384.

13. Singh S, Pai DR, Sinha NK, Kaur A, Soe HH, Barua A. Qualities of an effective teacher: what do medical teachers think? BMC Med Educ. 2013;13:128.

14. Lewis A. The issue of perception: some educational implications. Educare. 2001;30(1):272-288.

15. Al-Mohaimeed AA, Khan NK. Perceptions of Saudi medical students on the qualities of effective teachers. A cross-sectional study. Saudi Med J. 2014;35(2):183-188.

16. Murphy RM, Gray SA, Straja SR, Bogert MC. Student Learning Preferences and Teaching Implications. J Dent Educ. 2004;68(8): 859-866. 
17. Jahangiri L, McAndrew M, Muzaffar A, Mucciolo TW. Characteristics of effective clinical teachers identified by dental students: a qualitative study. Eur J Dent Educ. 2013;17(1):10-18.

18. Al-Sowygh ZH. Academic distress, perceived stress and coping strategies among dental students in Saudi Arabia. Saudi Dent J. 2013;25(3):97-105.

19. Al-Saleh SA, Al-Madi EM, Al-Angari NS, Al-Shehri HA, Shukri MM. Survey of perceived stress-inducing problems among dental students, Saudi Arabia. Saudi Dent J. 2010;22(2):83-88.
20. Al-Kabbaa AF, Ahmad HH, Saeed AA, Abdalla AM, Mustafa AA. Perception of the learning environment by students in a new medical school in Saudi Arabia: areas of concern. J Taibah Univ Med Sci. 2012; 7(2):69-75.

21. Ciraj AM, Abraham RR, Pallath V, Ramnarayan K, Kamath A, Kamath R. Exploring attributes of effective teachers-student perspectives from an Indian medical school. South-East Asian J Med Educ. 2013; 7(1):8-13.

\section{Publish your work in this journal}

Advances in Medical Education and Practice is an international, peerreviewed, open access journal that aims to present and publish research on Medical Education covering medical, dental, nursing and allied health care professional education. The journal covers undergraduate education, postgraduate training and continuing medical education including emerging trends and innovative models linking education, research, and health care services. The manuscript management system is completely online and includes a very quick and fair peer-review system. Visit http://www.dovepress.com/testimonials.php to read real quotes from published authors.

Submit your manuscript here: http://www.dovepress.com/advances-in-medical-education-and-practice-journal 